\title{
Asthmakranke Kinder erhalten zu häufig Antibiotika
}

\author{
Wenn sich bei Kindern mit Asthma bronchiale die \\ Atemwegssymptomatik verschlechtert, werden häu- \\ fig unnötigerweise Antibiotika verschrieben. Dies \\ zeigt eine britisch-niederländische Studie mit nahezu \\ zwei Millionen Kindern.
}

Die Exazerbation eines Asthmas bronchiale ist keine Indikation für eine Antibiotika-Therapie, denn nur sehr selten liegt eine bakterielle Infektion zugrunde. In dieser Empfehlung sind sich internationale Leitlinien einig.

Dennoch wird den Leitlinien häufig nicht Folge geleistet. Dies zeigen die Ergebnisse einer beim europäischen Lungenkongress

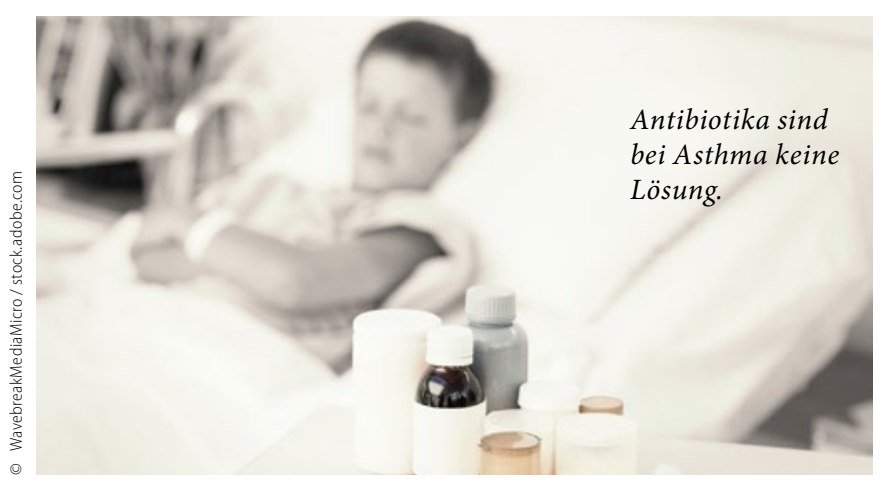

präsentierten Studie mit insgesamt 1,875 Millionen Kindern aus Großbritannien und den Niederlanden, von denen 180.000 Kinder an Asthma erkrankt waren.

In den Niederlanden, einem der Länder mit dem weltweit niedrigsten Antibiotika-Verbrauch, wurden jährlich 126 von 1.000 Kindern ohne Asthma mit Antibiotika behandelt. Von den asthmatischen Kindern erhielten 197 von 1.000 jedes Jahr Antibiotika. Der gleiche Trend zeigte sich in Großbritannien auf etwa doppelt so hohem Niveau: 250 von 1.000 Kinder ohne Asthma nahmen jährlich Antibiotika ein, sowie 374 von 1.000 Kindern mit Asthma.

Insgesamt lag die Wahrscheinlichkeit einer Antibiotika-Verschreibung bei Kindern mit Asthma um $60 \%$ höher.

Häufigste Ursachen für die Antibiotikaverschreibung bei asthmatischen Kindern waren Exazerbationen der obstruktiven Atemwegserkrankung oder eine akute Bronchitis, die in der Regel viral bedingt ist.

„Kinder mit schlecht kontrolliertem Asthma schlafen schlecht, bewegen sich nicht ausreichend und verschlechtern sich in den schulischen Leistungen. Deshalb muss die AsthmaMedikation optimiert werden. Wir wollen aber nicht, dass Antibiotika verschrieben werden, die in dieser Situation nicht hilfreich sind und sogar schädlich sein können“, resümierte Studienautorin Dr. Esmé Baan von der Erasmus Universität in Rotterdam.

Dr. med. Dirk Einecke

\section{Therapie der Überblähung bessert auch Herzfunktion}

\author{
Viele COPD-Patienten sterben an kardialen Begleiter- \\ krankungen. Eine Studie deutet jetzt an: Wenn bei \\ COPD die Überblähung behandelt wird, bessert sich \\ auch die Herzfunktion.
}

Kardiovaskuläre Begleiterkrankungen wie z.B. die Herzinsuffizienz tragen erheblich zu Morbidität und Mortalität von COPD-Patienten bei. Wenn die Patienten eine pulmonale Überblähung aufweisen, beeinträchtigt die damit einhergehende thorakale Druckerhöhung die Herzfunktion zusätzlich negativ.

Das Team vom Prof. Jens Hohlfeld vom Fraunhofer Institut der Medizinischen Hochschule Hannover ist der Frage nachgegangen, ob eine Entblähung der Lunge durch starke Broncholdilatatoren kardiale Funktionsparameter positiv beeinflusst. Dazu haben sie in einer doppelblinden Crossover-Studie 62 COPD-Patienten mit deutlicher Überblähung (Residualvolumen $135 \%$ oder mehr über der Norm), aber ohne relevante Herzerkrankung, mit Indacaterol/Glycopyrronium (Ultibro ${ }^{*}$ IND/GLY, 110/50 $\mu \mathrm{g}$ ) oder Placebo behandelt.
Nach zweiwöchiger Therapie mit IDN/GLY war die Herzfunktion der Patienten in klinisch relevantem Ausmaß verbessert. Das enddiastolische LV-Volumen (primärer Endpunkt) besserte sich signifikant um 10,27 ml. Das Herzauswurfvolumen stieg um 0,337 l/min an. Auch das rechtsventrikuläre enddiastolische Volumen besserte sich um 9,36 ml. Alle Unterschiede gegenüber Placebo waren hochsignifikant. Gleichzeitig verbesserte sich die Lungenfunktion, die $\mathrm{FEV}_{1}$ wurde um 0,42 1 erhöht, das Residualvolumen um 0,75 1 reduziert.

Dr. med. Dirk Einecke

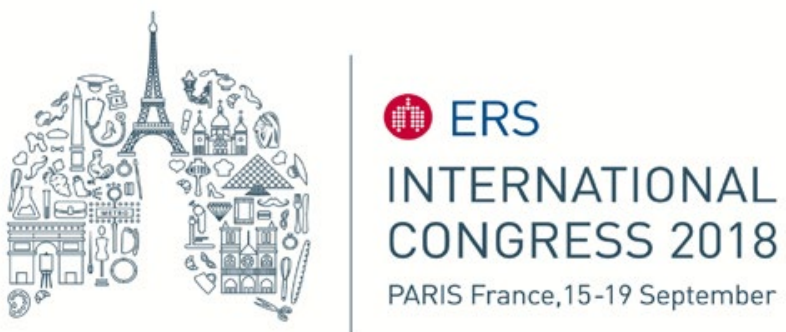

